\title{
Highly Emissive Self-Trapped Excitons in Fully Inorganic Zero- Dimensional Tin Halides
}

\author{
Bogdan M. Benin + Dmitry N. Dirin ${ }^{+}$,Viktoriia Morad, Michael Wörle, Sergii Yakunin, \\ Gabriele Rainò, Olga Nazarenko, Markus Fischer, Ivan Infante, and Maksym V. Kovalenko*
}

\begin{abstract}
The spatial localization of charge carriers to promote the formation of bound excitons and concomitantly enhance radiative recombination has long been a goal for luminescent semiconductors. Zero-dimensional materials structurally impose carrier localization and result in the formation of localized Frenkel excitons. Now the fully inorganic, perovskite-derived zero-dimensional $\mathrm{Sn}^{I I}$ material $\mathrm{Cs}_{4} \mathrm{SnBr}_{6}$ is presented that exhibits room-temperature broadband photoluminescence centered at $540 \mathrm{~nm}$ with a quantum yield $(Q Y)$ of $15 \pm 5 \%$. A series of analogous compositions following the general formula $C_{s_{4-x}} A_{x} \operatorname{Sn}\left(B r_{1-y} I_{y}\right)_{6}(A=R b, K$; $x \leq 1, y \leq 1)$ can be prepared. The emission of these materials ranges from $500 \mathrm{~nm}$ to $620 \mathrm{~nm}$ with the possibility to compositionally tune the Stokes shift and the self-trapped exciton emission bands.
\end{abstract}

Interest in low-dimensional metal halide semiconductors, ${ }^{[1]}$ and ultimately their zero-dimensional (0D) counterparts, ${ }^{[2]}$ has been spurred by the increasing interest in 3D lead halide perovskites. ${ }^{[3]}$ In recent years, lead halide perovskites have risen to prominence in the field of optoelectronics with their use in full-color imaging, ${ }^{[4]}$ photodetection, ${ }^{[5]} \mathrm{X}$-ray imaging, ${ }^{[6]}$ hard-radiation detection, ${ }^{[7]}$ solar cells, ${ }^{[8]}$ and light-emitting diodes, ${ }^{[9]}$ owing to their defect-tolerant photophysics and charge transport. ${ }^{[10]}$

$\left[{ }^{*}\right]$ B. M. Benin, ${ }^{[+]}$Dr. D. N. Dirin,,$^{[+]}$V. Morad, Dr. M. Wörle, Dr. S. Yakunin, Dr. G. Rainò, O. Nazarenko, M. Fischer, Prof. Dr. M. V. Kovalenko

Laboratory of Inorganic Chemistry, ETH Zürich

$\mathrm{CH}-8093$ Zürich (Switzerland)

E-mail: mvkovalenko@ethz.ch

B. M. Benin ${ }^{[+]}$Dr. D. N. Dirin, ${ }^{[+]}$V. Morad, Dr. S. Yakunin,

Dr. G. Rainò, O. Nazarenko, Prof. Dr. M. V. Kovalenko

Laboratory for Thin Films and Photovoltaics

Empa-Swiss Federal Laboratories for Materials

CH-8600 Dübendorf (Switzerland)

Dr. I. Infante

Department of Theoretical Chemistry, Faculty of Science

Vrije Universiteit Amsterdam

de Boelelaan 1083, 1081 HV Amsterdam (The Netherlands)

$\left.{ }^{+}\right]$These authors contributed equally.

(2) Supporting information and the ORCID identification number(s) for

ID the author(s) of this article can be found under: https://doi.org/10.1002/anie.201806452.

of (c) 2018 The Authors. Published by Wiley-VCH Verlag GmbH \& Co. $\mathrm{KGaA}$. This is an open access article under the terms of the Creative Commons Attribution-NonCommercial License, which permits use, distribution and reproduction in any medium, provided the original work is properly cited and is not used for commercial purposes.
As the dimensionality decreases, the metal halide octahedra become progressively less-connected and the optical and electrical properties shift away from those of a delocalized, 3D network towards 0D, molecular-like, isolated octahedra. In such structures, self-trapped excitons (STEs) form owing to the local deformation of the crystal lattice upon photoexcitation. This strong spatial localization, and the absence of electronic trapping processes that are inherent in electronically extended (higher-dimensionality) solids, favors radiative recombination. Previously, the spatial confinement of carriers in $3 \mathrm{D}$ perovskites has been attained through crystal size control at the nanoscale (that is, top-down and bottom-up synthesis of nanocrystals) ${ }^{[11]}$ In the case of OD materials, such elaborate crystal size engineering is not required as the optical properties are instead governed by their structural dimensionality. Highly localized Frenkel-like excitons are formed instead of Wannier-Mott type excitons.

The library of 0D metal halides with octahedral building units includes both lead-based and lead-free compounds: $\mathrm{Ti}^{\mathrm{IV}},{ }^{[12]} \mathrm{Hf}^{\mathrm{IV}},{ }^{\mathrm{[13]}} \mathrm{Zr}^{\mathrm{IV}},{ }^{[14]} \mathrm{Pd}^{\mathrm{IV}},{ }^{[15]} \mathrm{Pb}^{\mathrm{II}},{ }^{[16]} \mathrm{Sn}^{\mathrm{IV}},{ }^{\mathrm{I17]}} \mathrm{Te}^{\mathrm{IV}},{ }^{[18]} \mathrm{Sb}^{\mathrm{III}},{ }^{[19]}$ and $\mathrm{Bi}^{\mathrm{III}} \cdot{ }^{[20]}$ However, only several of these examples exhibit photoluminescence (PL) at room temperature (RT), and this emission is seldom characterized by a high PL quantum yield (QY). The first examples with high QYs in excess of $50 \%$ were demonstrated only recently: $\left(\mathrm{C}_{4} \mathrm{~N}_{2} \mathrm{H}_{14} \mathrm{Br}\right){ }_{4} \mathrm{SnBr}_{6}(\mathrm{QY}=$ $95 \% \pm 5 \%)$ and $\left(\mathrm{C}_{4} \mathrm{~N}_{2} \mathrm{H}_{14} \mathrm{I}\right)_{4} \mathrm{SnI}_{6}(\mathrm{QY}=75 \% \pm 4 \%) .{ }^{[21]}$ Both structures are constructed from disconnected $\left[\mathrm{SnX}_{6}\right]^{4-}$ octahedra, separated by large organic cations with a distance of more than $1 \mathrm{~nm}$ between $\mathrm{Sn}^{2+}$ centers.

Given the high PL QY of these hybrid materials and their novel approach towards exciton localization, herein we chose to pursue fully inorganic analogues such as $\mathrm{Cs}_{4} \mathrm{SnBr}_{6}$. While several studies have reported on the structure and basic properties of $\mathrm{Cs}_{4} \mathrm{SnBr}_{6}$, none have observed $\mathrm{PL}$ at $\mathrm{RT}^{[22]}$ Recently, calculations have shown that the $\mathrm{Cs}_{4} \mathrm{SnBr}_{6}$ phase should have a band gap of $3.37 \mathrm{eV} \cdot{ }^{[23]}$ We prepared $\mathrm{Cs}_{4-x} \mathrm{~A}_{x} \mathrm{Sn}$ $\left(\mathrm{Br}_{1-y} \mathrm{I}_{y}\right)_{6}(\mathrm{~A}=\mathrm{Rb}, \mathrm{K})$ materials using a simple solid-state heat-and-beat approach, characterized them structurally, and found them to be luminescent at RT.

According to the $\mathrm{CsBr}-\mathrm{SnBr}_{2}$ pseudo-binary phase diagram (Figure $1 \mathrm{a}$ ), $\mathrm{Cs}_{4} \mathrm{SnBr}_{6}$ melts incongruently and competes with the decomposition into the black $\mathrm{CsSnBr}_{3}$ and $\mathrm{CsBr}$. Therefore, phase-pure $\mathrm{Cs}_{4} \mathrm{SnBr}_{6}$ cannot be obtained by cooling from a melt of this composition. Instead, solid pellets of a mixture of $\mathrm{CsBr}$ (4.5 equiv.) and $\mathrm{SnBr}_{2}$ (1 equiv.) were repeatedly heated to $350^{\circ} \mathrm{C}$ for $60 \mathrm{~h}$ and reground in a glovebox between heating cycles. The highlighted green region in Figure $1 \mathrm{a}$ represents the experimental conditions that were found to yield the purest materials, that is, at temperatures 


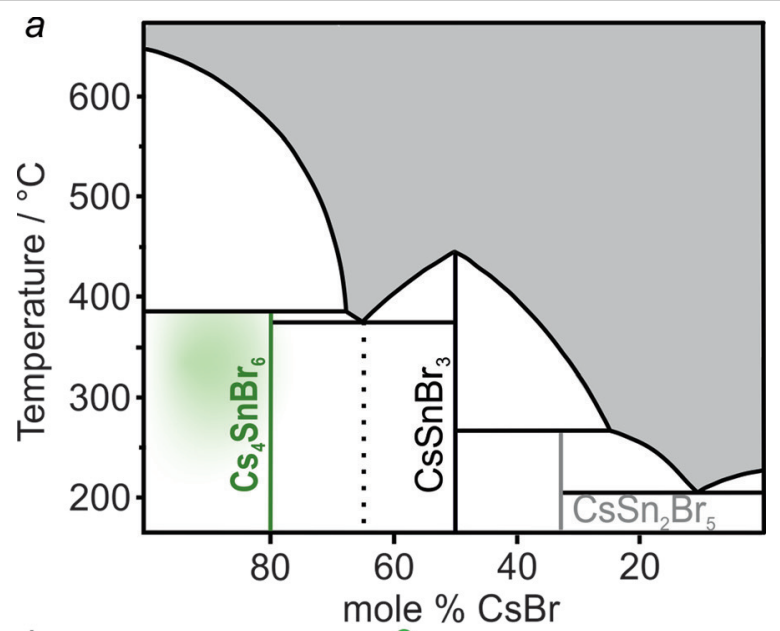

$b$

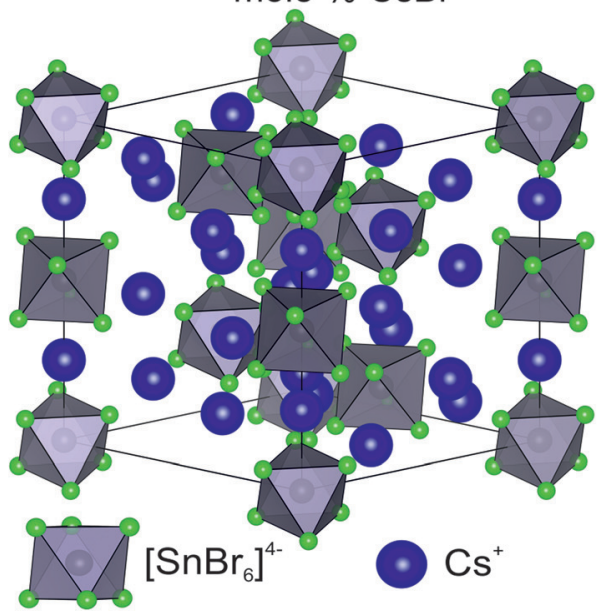

C

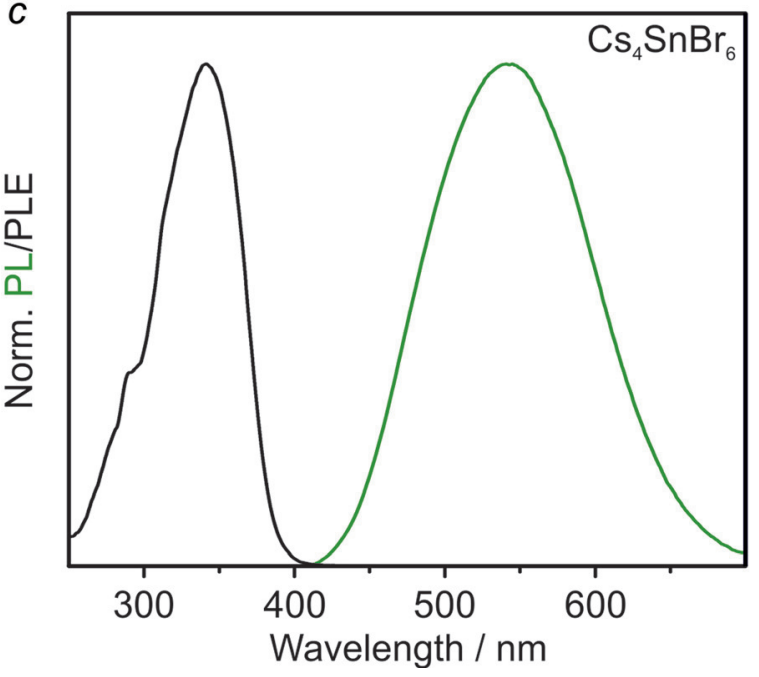

Figure 1. a) The pseudo-binary $\mathrm{CsBr}-\mathrm{SnBr}_{2}$ phase diagram. ${ }^{\text {[22a] }}$ The highlighted green region represents the experimental conditions found to yield the purest $\mathrm{Cs}_{4} \mathrm{SnBr}_{6}$ material. b) The crystal structure of $\mathrm{Cs}_{4} \mathrm{SnBr}_{6}$ viewed along the (111) axis with $\left[\mathrm{SnBr}_{6}\right]^{4-}$ octahedra (gray with green bromine atoms) separated by $\mathrm{Cs}^{+}$cations (blue). c) PL and PLE spectra for $\mathrm{Cs}_{4} \mathrm{SnBr}_{6}$ at RT.

below the decomposition point of $\mathrm{Cs}_{4} \mathrm{SnBr}_{6}$ (Supporting Information, Figures S1, S2; Tables S1, S2). Single crystals of $\mathrm{Cs}_{4} \mathrm{SnBr}_{6}$ were obtained by tempering a solid pellet at $350^{\circ} \mathrm{C} . \mathrm{Cs}_{4} \mathrm{SnBr}_{6}$ crystallizes in a trigonal crystal system $(R \overline{3} c$ space group; Figure 1b; Supporting Information, Tables S3S9), wherein $\left[\mathrm{SnBr}_{6}\right]^{4-}$ octahedra are separated by $\mathrm{Cs}^{+}$ cations. The $\mathrm{Cs}^{+}$cations occupy two distinct crystallographic positions (Supporting Information, Figure S3).

Unlike the isostructural $\mathrm{Cs}_{4} \mathrm{PbBr}_{6}$, which shows narrow excitonic PL only at low temperatures and at wavelengths $<400 \mathrm{~nm},{ }^{[16]} \mathrm{Cs}_{4} \mathrm{SnBr}_{6}$ exhibits broad-band green-yellow PL at RT from STEs (peak maximum at $540 \mathrm{~nm}$, Figure 1c). Upon measuring the PL excitation (PLE) and absorption spectra it was found that $\mathrm{Cs}_{4} \mathrm{SnBr}_{6}$ resembled a molecular material with a sharp excitation peak at $340 \mathrm{~nm}$ yielding a large Stokes shift of about $1.2 \mathrm{eV}$ (Supporting Information, Figure S4). A PLQY of $15 \pm 5 \%$ was measured at RT. PLE and PL spectra were found to be tunable through the partial substitution of both A-site cations (Cs with $\mathrm{Rb}, \mathrm{K}$ ) and the halide anions ( $\mathrm{Br}$ with I). Na was not observed to substitute Cs (Supporting Information, Figure S5).

In $\left(\mathrm{C}_{4} \mathrm{~N}_{2} \mathrm{H}_{14} \mathrm{X}\right)_{4} \mathrm{SnX} \mathrm{X}_{6}(\mathrm{X}=\mathrm{Br} / \mathrm{I}),{ }^{[21]}$ the addition of iodide red-shifts both the excitation and STE emission spectra. Similarly, the PL of $\mathrm{Cs}_{4} \mathrm{SnX}_{6}$ shifts to $620 \mathrm{~nm}$ (orange emission) at a $\mathrm{Br}: \mathrm{I}$ ratio of ca. 1:1 (Figure 2a). In agreement with Vegard's law, a linear change in both the $a$ and $c$ lattice parameters was observed over the range of compositions from $\mathrm{Cs}_{4} \mathrm{SnBr}_{6}$ to $\mathrm{Cs}_{4} \mathrm{SnI}_{6}$ (Supporting Information, Figures S6, S7; Tables S10, S11). Samples with greater than 50\% substitution by iodide, however, did not exhibit PL at RT and were not investigated further.

While bromide and iodide occupy the same general position within the structure of $\mathrm{Cs}_{4} \mathrm{SnBr}_{6}, \mathrm{Rb}^{+}$and $\mathrm{K}^{+}$could potentially substitute two distinct crystallographic positions of $\mathrm{Cs}^{+}$(Supporting Information, Figure S3). Substitution by $\mathrm{Rb}^{+}$or $\mathrm{K}^{+}$occurred only on the Cs 2 site (1/4 of all Cs, six-fold coordination, Figure $2 \mathrm{~b}$; Supporting Information, Figure S8, Tables S12, S13), which explains the observed experimental $25 \%$-limit for substitution (Supporting Information, Figure S9). Plotting the lattice constants against the molar fractions of $\mathrm{K}^{+}$or $\mathrm{Rb}^{+}$ions, estimated from Rietveld refinement and energy-dispersive X-ray spectroscopy (EDS), yields a seemingly linear trend for the $c$ parameter, in agreement with Vegard's law, whereas the $a$ parameter increases only slightly (Figure 2c; Supporting Information, Figures S9-S11). The site affected is part of an infinite chain of $\left[\mathrm{SnBr}_{6}\right]^{4-}$ octahedra separated by $\mathrm{Cs} / \mathrm{Rb} / \mathrm{K}$ ions. Since the chain is oriented parallel to the $c$-axis, substitution by $\mathrm{Rb}$ or $\mathrm{K}$ will cause the largest effect along this axis resulting in a decrease in the $c$ parameter.

The substitution of $\mathrm{Cs}^{+}$by $\mathrm{Rb}^{+}$or $\mathrm{K}^{+}$results in a blue-shift of the PL maximum. This shift is dependent on both the degree of substitution and on the identity of the substituting cation. For $25 \%$ substitution, $\mathrm{Rb}^{+}$shifts the PL peak to $519 \mathrm{~nm}$, whereas $\mathrm{K}^{+}$yields a PL peak at $500 \mathrm{~nm}$ (Figure $2 \mathrm{~d}$ ). Strikingly, the PLE remains unaffected. The same scenario was observed for the other examined $\mathrm{Br}$ :I ratios (ca. 5:1, 2:1, 1:1; Figure 2e; Figure S12, Tables S14, S15).

Temperature-dependent PL spectra were measured down to $6 \mathrm{~K}$ (Supporting Information, Figures S13, S14). It was found that the PL intensity increased with decreasing temperature and, in the case of $\mathrm{Cs}_{4} \mathrm{SnBr}_{6}$, the emission intensity reached a maximum at about $200 \mathrm{~K}$. Given a RT QY of $15 \pm$ 

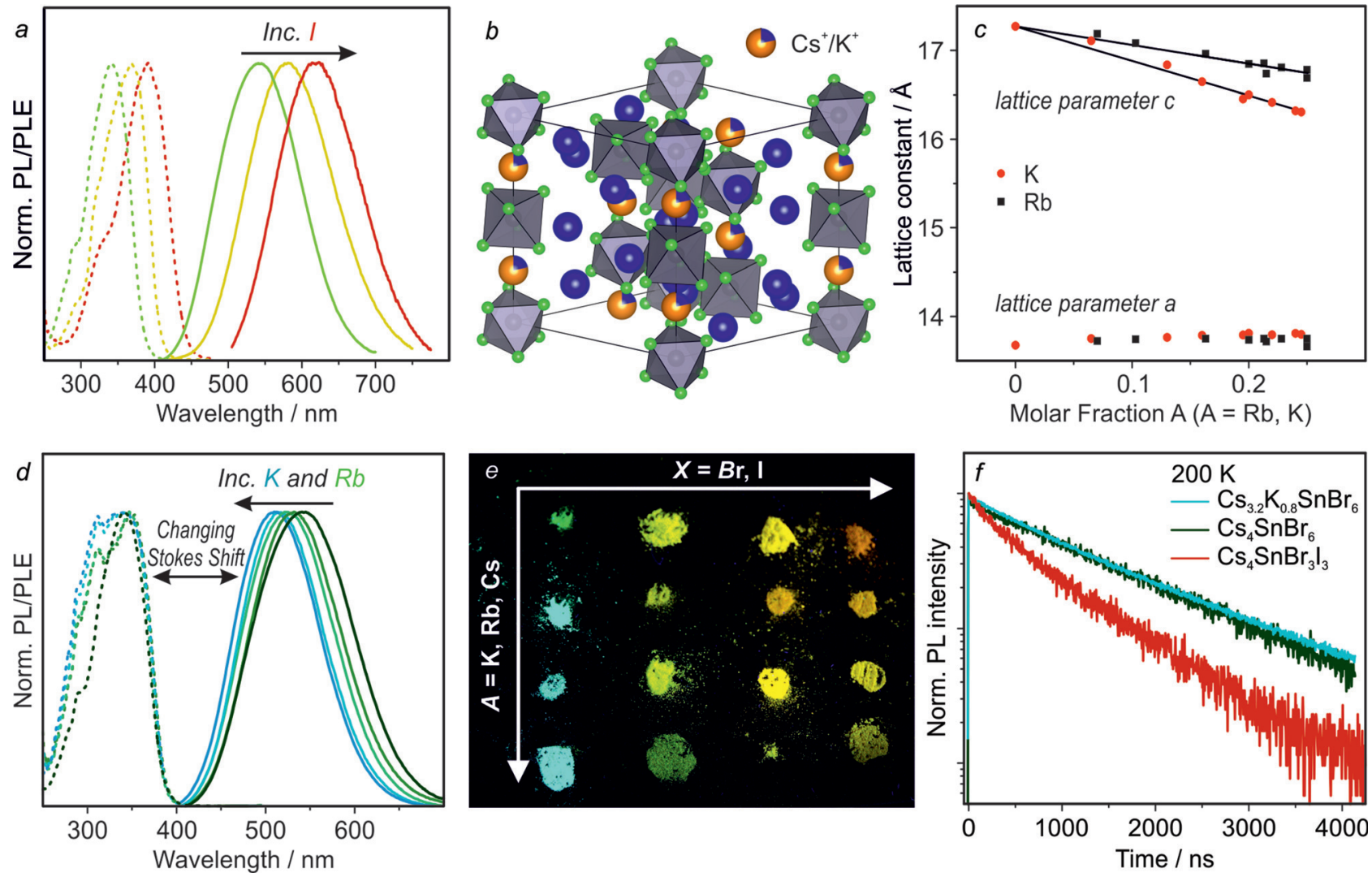

Figure 2. Structural and optical characterization of $\mathrm{Cs}_{4-x} \mathrm{~A}_{x} \mathrm{Sn}(\mathrm{Br}, \mathrm{I})_{6}$ compounds $(\mathrm{A}=\mathrm{K}, \mathrm{Rb})$. a) $\mathrm{PL}$ and PLE spectra of $\mathrm{Cs} \mathrm{s}_{4} \mathrm{Sn}(\mathrm{Br}, \mathrm{I})_{6}$. b) $\mathrm{Crystal}$ structure of $\mathrm{Cs}_{3.2} \mathrm{~K}_{0.8} \mathrm{SnBr}_{6}$ determined by Rietveld refinement. c) The change in the $a$ and $c$ lattice parameters upon $\mathrm{Cs}^{+}$substitution by $\mathrm{Rb}^{+}$and $\mathrm{K}^{+}$. d) $\mathrm{PL}$ and PLE spectra for $\mathrm{Rb}^{+}$or $\mathrm{K}^{+}$substituted compounds. e) Image of $\mathrm{Cs}_{4-x} \mathrm{~A}_{x} \mathrm{Sn}(\mathrm{Br}, \mathrm{I})_{6}$ powders under $365 \mathrm{~nm} \mathrm{UV}$ light. f) TRPL of $\mathrm{Cs}_{4} \mathrm{SnBr}_{6}, \mathrm{Cs}_{3.2} \mathrm{~K}_{0.8} \mathrm{SnBr}_{6}$, and $\mathrm{Cs}_{4} \mathrm{SnBr}_{3} \mathrm{I}_{3}$ at $200 \mathrm{~K}$.

$5 \%$, the QY of $\mathrm{Cs}_{4} \mathrm{SnBr}_{6}$ is estimated to be near-unity at $200 \mathrm{~K}$ (Supporting Information, Figure S15a). At $6 \mathrm{~K}$, no higherenergy emission, that is, from free excitons, could be observed in $\mathrm{Cs}_{4} \mathrm{SnBr}_{6}$ or $\mathrm{Cs}_{4} \mathrm{SnBr}_{3} \mathrm{I}_{3}$ (Supporting Information, Figures S14, S15b).

The time-resolved PL (TRPL) of $\mathrm{Cs}_{4} \mathrm{SnBr}_{6}$ at RT exhibits a monoexponential decay with an average lifetime of $540 \mathrm{~ns}$ (Supporting Information, Figure S16). TRPL decays were then recorded at $200 \mathrm{~K}$ (the temperature that corresponds to highest QY, Figure $2 \mathrm{f}$; Supporting Information, Figure S15), and it was observed that the lifetime increased to $1381 \mathrm{~ns}$ (1424 ns for K-substitution), while remaining monoexponential (Figure $2 \mathrm{f}$ ). Substitution with iodide accelerated the average lifetime $\left(600 \mathrm{~ns}\right.$ at $200 \mathrm{~K}$ for $\mathrm{Cs}_{4} \mathrm{SnBr}_{3} \mathrm{I}_{3}$, Figure $2 \mathrm{f}$; see the Supporting Information, Figure S16b for RT comparison). Additionally, the radiative lifetime was found to be insensitive towards dilution with $\mathrm{CsBr}$, excitation intensity, crystallinity, and encapsulation within a UV-curable epoxy (Supporting Information, Figure S16c,d), indicating a lack of surface effects on PL properties in these 0D materials.

Broad-band, strongly Stokes-shifted emission with relatively long radiative lifetimes indicates the formation of STEs (Figure 3a). As in molecular complexes and similarly small entities, structural changes occur between the ground state and the excited state. Emission from STEs is then somewhat similar to an indirect-gap optical transition since coupling to phonons is required. ${ }^{[24]}$ Besides 0D-tin halides, ${ }^{[21 b]}$ emission from STEs has also been observed in 1D- and 2D-layered materials. ${ }^{[25]}$

To rationalize the effect of A-site substitution observed in these materials, calculations of the partial density of states (DOS) by density functional theory (DFT) were utilized (Figure 3b; Supporting Information, Figure S17, Table S16).

A $1 \times 1 \times 1$ unit cell ( 66 atoms) was used as a model system for $\mathrm{Cs}_{4} \mathrm{SnBr}_{6}, \mathrm{Cs}_{3} \mathrm{RbSnBr}_{6}$, and $\mathrm{Cs}_{3} \mathrm{KSnBr}_{6}$ materials. The electronic states were found to be highly localized in all three compositions and the band gap was found to consist of Sn $5 \mathrm{~s}$, $\mathrm{Br} 5 \mathrm{p}$ (conduction band/LUMO) and $\mathrm{Sn} 5 \mathrm{p}, \mathrm{Br} 5 \mathrm{p}$ orbitals (valence band/HOMO). A-cation orbitals do not significantly contribute to HOMO and LUMO states (Supporting Information, Figure S17). This is corroborated by the experiment given that A-site substitution did not substantially affect the PLE spectra.

It was previously shown that both tin- and lead-halide octahedra distort significantly upon photoexcitation in lowdimensional materials. ${ }^{[26]}$ By modeling the excited state and ground state geometries, we find that the extent of distortion was the principle reason for the Stokes shift (Figure 3b). A pseudo-Jahn-Teller distortion was observed with elongation of up to $17 \%$ in the axial $\mathrm{Sn}-\mathrm{Br}$ bonds, and a contraction of up to $7 \%$ in the equatorial bonds. This distortion was found to be greatest in $\mathrm{Cs}_{4} \mathrm{SnBr}_{6}$ and decreased from $\mathrm{Cs}^{+}$to $\mathrm{Rb}^{+}$to $\mathrm{K}^{+}$ 


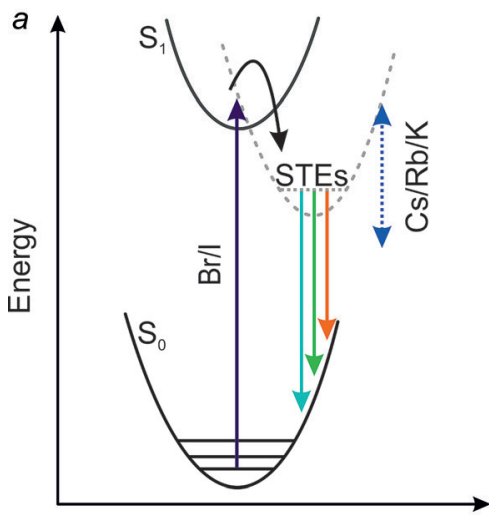

Coordinate
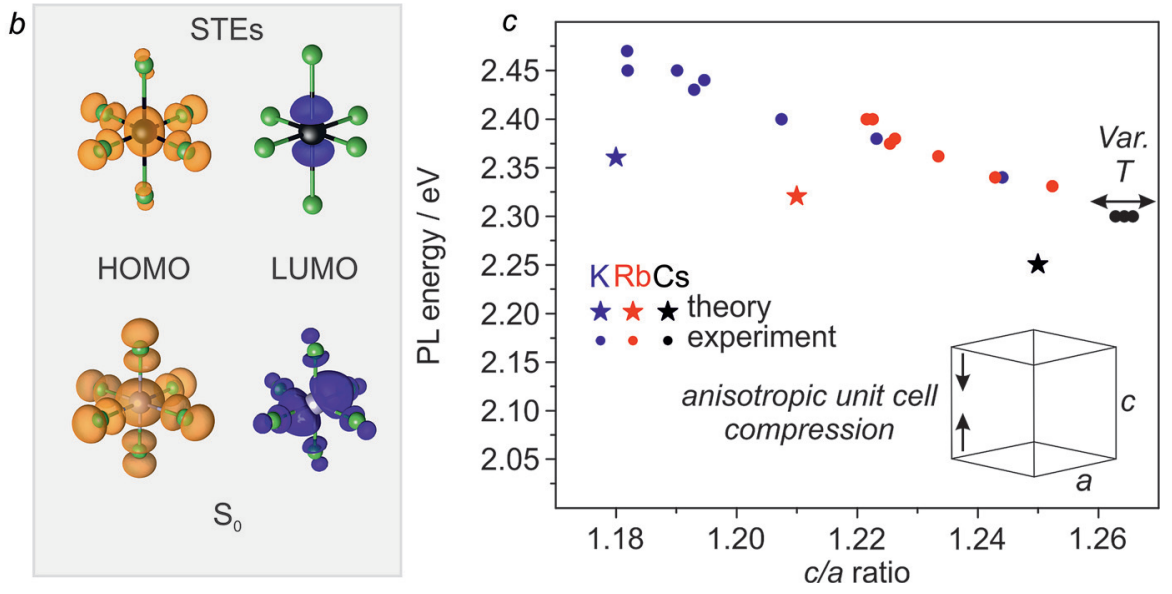

Figure 3. a) Generic configurational coordinate diagram illustrating the origin of STE PL in $\mathrm{Cs}_{4-x} A_{x} S n\left(B_{1-y} \mathrm{I}_{y}\right)_{6}$. b) Ground-state and excited-state (STE) HOMOs and LUMOs. c) Experimental and theoretical results demonstrating that PL energy varies linearly with the ratio of c-axis to a-axis length. Variable-temperature measurements (three data points; black circles) are plotted for $\mathrm{Cs}_{4} \mathrm{SnBr}_{6}$ at $100 \mathrm{~K}, 200 \mathrm{~K}$, and $273 \mathrm{~K}$.

(Supporting Information, Table S17). In other words, the energy required for distortion correlates well with the measured Stokes shift. Larger distortion is allowed by greater distance between the octahedra; primarily along the $c$-axis. The ratio between the lengths of the $c$ - and $a$-axes was found to correlate most strongly with PL energy, experimentally and in calculations (Figure $3 \mathrm{c}$ ). On the other hand, isotropic changes to the unit cell (that is, contraction during cooling) do not affect the PL (Supporting Information, Table S18).

In summary, several new $0 \mathrm{D}$ tin halides with the general formula $\mathrm{Cs}_{4-x} \mathrm{~A}_{x} \mathrm{Sn}\left(\mathrm{Br}_{1-y} \mathrm{I}_{y}\right)_{6}$ have been found to exhibit broad-band RT PL that is tunable from $500 \mathrm{~nm}$ to $620 \mathrm{~nm}$. The PL peak position and Stokes shifts can be concomitantly adjusted by the substitution of $\mathrm{Cs}^{+}$with either $\mathrm{Rb}^{+}$or $\mathrm{K}^{+}$as well as $\mathrm{Br}^{-}$by $\mathrm{I}^{-}$. PL properties were rationalized by the DFT analysis of STEs. Future studies might concern applications of such materials in luminescent solar concentrators and light emitting devices, harnessing their structural tunability and fully inorganic compositions.

\section{Experimental Section}

Materials and methods are included in the Supporting Information. Further details on the crystal structure investigation may be obtained from the Fachinformationszentrum Karlsruhe, 76344 Eggenstein-Leopoldshafen, Germany (fax: $(+49)$ 7247-808-666; e-mail: crysdata@fiz-karlsruhe.de), on quoting the depository numbers CSD-434641, 434642, 434643, 434644, 434645, 434646, and 434647.

\section{Acknowledgements}

We thank Dr. F. Krumeich for EDS measurements and acknowledge the support of the Scientific Center for Optical and Electron Microscopy (ScopeM) of the Swiss Federal Institute of Technology ETHZ. We thank Michael Solar for single-crystal X-ray diffraction measurements. This work was financially supported by the European Union through the FP7 (ERC Starting Grant NANOSOLID, GA No. 306733) and through the Horizon-2020 (Marie-Skłodowska Curie ITN network PHONSI, H2020-MSCA-ITN-642656). Authors thank IBM-Zurich Research, in particular Dr. T. Stöferle and Dr. R. F. Mahrt, for support with low-temperature PL experiments. I.I. would like to thank The Netherlands Organization of Scientific Research (NWO) for providing financial support within the Innovational Research Incentive (Vidi) Scheme (Grant no. 723.013.002). DFT calculations were carried out on the Dutch national e-infrastructure with the support of SURF Cooperative.

\section{Conflict of interest}

The authors declare no conflict of interest.

Keywords: luminescence - perovskites - self-trapped excitons . solid-state synthesis $\cdot$ tin

How to cite: Angew. Chem. Int. Ed. 2018, 57, 11329-11333 Angew. Chem. 2018, 130, 11499-11503

[1] a) D. B. Mitzi, C. A. Felid, W. T. A. Harrison, A. M. Guloy, Nature 1994, 369, 467-469; b) D. B. Mitzi, K. Liang, S. Wang, Inorg. Chem. 1998, 37, 321-327; c) Z. Xu, D. B. Mitzi, Inorg. Chem. 2003, 42, 6589-6591; d) L. Pedesseau, D. Sapori, B. Traore, R. Robles, H. H. Fang, M. A. Loi, H. Tsai, W. Nie, J. C. Blancon, A. Neukirch, S. Tretiak, A. D. Mohite, C. Katan, J. Even, M. Kepenekian, ACS Nano 2016, 10, 9776-9786; e) L. Mao, H. Tsai, W. Nie, L. Ma, J. Im, C. C. Stoumpos, C. D. Malliakas, F. Hao, M. R. Wasielewski, A. D. Mohite, M. G. Kanatzidis, Chem. Mater. 2016, 28, 7781-7792; f) C. C. Stoumpos, D. H. Cao, D. J. Clark, J. Young, J. M. Rondinelli, J. I. Jang, J. T. Hupp, M. G. Kanatzidis, Chem. Mater. 2016, 28, 2852-2867; g) H. Tsai, W. Nie, J. C. Blancon, C. C. Stoumpos, R. Asadpour, B. Harutyunyan, A. J. Neukirch, R. Verduzco, J. J. Crochet, S. Tretiak, L. Pedesseau, J. Even, M. A. Alam, G. Gupta, J. Lou, P. M. Ajayan, M. J. Bedzyk, M. G. Kanatzidis, Nature 2016, 536, 312-316; h) L. Mao, Y. Wu, C. C. Stoumpos, M. R. Wasielewski, M. G. Kanatzidis, J. Am. Chem. Soc. 2017, 139, 5210-5215; i) L. Mao, Y. Wu, C. C. Stoumpos, B. Traore, C. Katan, J. Even, M. R. Wasielewski, M. G. Kanatzidis, J. Am. Chem. Soc. 2017, 139, 
$11956-11963$; j) D. H. Cao, C. C. Stoumpos, T. Yokoyama, J. L. Logsdon, T.-B. Song, O. K. Farha, M. R. Wasielewski, J. T. Hupp, M. G. Kanatzidis, ACS Energy Lett. 2017, 2, 982-990; k) C. M. M. Soe, C. C. Stoumpos, M. Kepenekian, B. Traore, H. Tsai, W. Nie, B. Wang, C. Katan, R. Seshadri, A. D. Mohite, J. Even, T. J. Marks, M. G. Kanatzidis, J. Am. Chem. Soc. 2017, 139 , 16297-16309; 1) O. Nazarenko, M. R. Kotyrba, M. Worle, E. Cuervo-Reyes, S. Yakunin, M. V. Kovalenko, Inorg. Chem. 2017, 56, $11552-11564 ; \mathrm{m})$ C. C. Stoumpos, L. Mao, C. D. Malliakas, M. G. Kanatzidis, Inorg. Chem. 2017, 56, 56-73; n) O. Nazarenko, M. R. Kotyrba, S. Yakunin, M. Aebli, G. Raino, B. M. Benin, M. Worle, M. V. Kovalenko, J. Am. Chem. Soc. 2018, 140 , $3850-3853$; o) M. D. Smith, H. I. Karunadasa, Acc. Chem. Res. 2018, 51, 619-627.

[2] a) M. I. Saidaminov, O. F. Mohammed, O. M. Bakr, ACS Energy Lett. 2017, 2, 889-896; b) H. Lin, C. Zhou, Y. Tian, T. Siegrist, B. Ma, ACS Energy Lett. 2018, 3, 54-62; c) Q. A. Akkerman, A. L. Abdelhady, L. Manna, J. Phys. Chem. Lett. 2018, 9, 2326-2337.

[3] a) M. A. Green, A. Ho-Baillie, H. J. Snaith, Nat. Photonics 2014 8, 506-514; b) J. S. Manser, J. A. Christians, P. V. Kamat, Chem. Rev. 2016, 116, 12956-13008; c) Q. A. Akkerman, G. Raino, M. V. Kovalenko, L. Manna, Nat. Mater. 2018, 17, 394-405.

[4] S. Yakunin, Y. Shynkarenko, D. N. Dirin, I. Cherniukh, M. V. Kovalenko, NPG Asia Mater. 2017, 9, e431.

[5] a) X. Hu, X. Zhang, L. Liang, J. Bao, S. Li, W. Yang, Y. Xie, $A d v$ Funct. Mater. 2014, 24, 7373-7380; b) L. Dou, Y. M. Yang, J. You, Z. Hong, W. H. Chang, G. Li, Y. Yang, Nat. Commun. 2014 $5,1-6$.

[6] S. Yakunin, M. Sytnyk, D. Kriegner, S. Shrestha, M. Richter, G. J. Matt, H. Azimi, C. J. Brabec, J. Stangl, M. V. Kovalenko, W. Heiss, Nat. Photonics 2015, 9, 444-449.

[7] a) C. C. Stoumpos, C. D. Malliakas, J. A. Peters, Z. Liu, M. Sebastian, J. Im, T. C. Chasapis, A. C. Wibowo, D. Y. Chung, A. J. Freeman, B. W. Wessels, M. G. Kanatzidis, Cryst. Growth Des. 2013, 13, 2722-2727; b) S. Yakunin, D. N. Dirin, Y Shynkarenko, V. Morad, I. Cherniukh, O. Nazarenko, D. Kreil, T. Nauser, M. V. Kovalenko, Nat. Photonics 2016, 10, 585-589.

[8] a) M. M. Lee, J. Teuscher, T. Miyasaka, T. N. Murakami, H. J. Snaith, Science 2012, 338, 643-647; b) J. Burschka, N. Pellet, S. J. Moon, R. Humphry-Baker, P. Gao, M. K. Nazeeruddin, M. Gratzel, Nature 2013, 499, 316-319.

[9] Z.-K. Tan, R. S. Moghaddam, M. L. Lai, P. Docampo, R. Higler, F. Deschler, M. Price, A. Sadhanala, L. M. Pazos, D. Credgington, F. Hanusch, T. Bein, H. J. Snaith, R. H. Friend, Nat. Nanotechnol. 2014, 9, 687-692.

[10] a) R. E. Brandt, V. Stevanović, D. S. Ginley, T. Buonassisi, MRS Commun. 2015, 5, 265-275; b) O. Yaffe, Y. Guo, L. Z. Tan, D. A. Egger, T. Hull, C. C. Stoumpos, F. Zheng, T. F. Heinz, L. Kronik, M. G. Kanatzidis, J. S. Owen, A. M. Rappe, M. A. Pimenta, L. E. Brus, Phys. Rev. Lett. 2017, 118, 136001; c) K. Miyata, T. L. Atallah, X.-Y. Zhu, Sci. Adv. 2017, 3, e1701469.

[11] a) L. C. Schmidt, A. Pertegas, S. Gonzalez-Carrero, O. Malinkiewicz, S. Agouram, G. Minguez Espallargas, H. J. Bolink, R. E. Galian, J. Perez-Prieto, J. Am. Chem. Soc. 2014, 136, 850-853; b) L. Protesescu, S. Yakunin, M. I. Bodnarchuk, F. Krieg, R. Caputo, C. H. Hendon, R. X. Yang, A. Walsh, M. V. Kovalenko, Nano Lett. 2015, 15, 3692-3696; c) D. N. Dirin, L. Protesescu, D. Trummer, I. V. Kochetygov, S. Yakunin, F. Krumeich, N. P. Stadie, M. V. Kovalenko, Nano Lett. 2016, 16, 5866-5874, d) Q. A. Akkerman, S. G. Motti, A. R. Srimath Kandada, E. Mosconi, V. D’Innocenzo, G. Bertoni, S. Marras, B. A. Kamino, L. Miranda, F. De Angelis, A. Petrozza, M. Prato, L. Manna, J. Am. Chem. Soc. 2016, 138, 1010-1016; e) H. Huang, Q. Xue, B. Chen, Y. Xiong, J. Schneider, C. Zhi, H. Zhong, A. L. Rogach, Angew. Chem. Int. Ed. 2017, 56, 9571-9576; Angew. Chem. 2017, 129, 9699-9704; f) L. Protesescu, S. Yakunin, O. Naza- renko, D. N. Dirin, M. V. Kovalenko, ACS Appl. Nano Mater. 2018, $1,1300-1308$

[12] M. Chen, M.-G. Ju, A. D. Carl, Y. Zong, R. L. Grimm, J. Gu, X. C. Zeng, Y. Zhou, N. P. Padture, Joule 2018, 2, 558-570.

[13] a) B. Kang, K. Biswas, J. Phys. Chem. C 2016, 120, 12187-12195; b) R. Král, V. Babin, E. Mihóková, M. Buryi, V. V. Laguta, K. Nitsch, M. Nikl, J. Phys. Chem. C 2017, 121, 12375-12382.

[14] K. Saeki, Y. Fujimoto, M. Koshimizu, D. Nakauchi, H. Tanaka, T. Yanagida, K. Asai, Jpn. J. Appl. Phys. 2018, 57, 030310.

[15] N. Sakai, A. A. Haghighirad, M. R. Filip, P. K. Nayak, S. Nayak, A. Ramadan, Z. Wang, F. Giustino, H. J. Snaith, J. Am. Chem. Soc. 2017, 139, 6030-6033.

[16] M. Nikl, E. Mihokova, K. Nitsch, F. Somma, C. Giampaolo, G. P. Pazzi, P. Fabeni, S. Zazubovich, Chem. Phys. Lett. 1999, 306, $280-284$.

[17] a) B. Lee, C. C. Stoumpos, N. Zhou, F. Hao, C. Malliakas, C. Y. Yeh, T. J. Marks, M. G. Kanatzidis, R. P. Chang, J. Am. Chem. Soc. 2014, 136, 15379-15385; b) A. Kaltzoglou, M. Antoniadou, A. G. Kontos, C. C. Stoumpos, D. Perganti, E. Siranidi, V. Raptis, K. Trohidou, V. Psycharis, M. G. Kanatzidis, P. Falaras, J. Phys. Chem. C 2016, 120, 11777-11785.

[18] a) R. Wernicke, H. Kupka, W. Ensslin, H.-H. Schmidtke, Chem. Phys. 1980, 47, 235 -244; b) G. Blasse, G. J. Dirksen, W. Abriel, Chem. Phys. Lett. 1987, 136, 460-464; c) T. V. Sedakova, A. G. Mirochnik, V. E. Karasev, Opt. Spectrosc. 2011, 110, 755-761; d) B. V. Bukvetskii, T. V. Sedakova, A. G. Mirochnik, Russ. J. Coord. Chem. 2012, 38, 106-110.

[19] a) T. V. Sedakova, A. G. Mirochnik, V. E. Karasev, Opt. Spectrosc. 2008, 105, 517-523; b) V. I. Vovna, A. A. Dotsenko, V. V. Korochentsev, O. L. Shcheka, I. S. Os'mushko, A. G. Mirochnik, T. V. Sedakova, V. I. Sergienko, J. Mol. Struct. 2015, 1091, $138-$ 146; c) C. Zhou, M. Worku, J. Neu, H. Lin, Y. Tian, S. Lee, Y. Zhou, D. Han, S. Chen, A. Hao, P. I. Djurovich, T. Siegrist, M.-H. Du, B. Ma, Chem. Mater. 2018, 30, 2374-2378.

[20] N. Elfaleh, S. Kamoun, J. Organomet. Chem. 2016, 819, 95-102. [21] a) C. Zhou, Y. Tian, Z. Yuan, H. Lin, B. Chen, R. Clark, T. Dilbeck, Y. Zhou, J. Hurley, J. Neu, T. Besara, T. Siegrist, P. Djurovich, B. Ma, ACS Appl. Mater. Interfaces 2017, 9, 4457944583; b) C. Zhou, H. Lin, Y. Tian, Z. Yuan, R. Clark, B. Chen, L. J. van de Burgt, J. C. Wang, Y. Zhou, K. Hanson, Q. J. Meisner, J. Neu, T. Besara, T. Siegrist, E. Lambers, P. Djurovich, B. Ma, Chem. Sci. 2018, 9, 586-593.

[22] a) R. H. Andrews, S. J. Clark, J. D. Donaldson, J. Chem. Soc. Dalton Trans. 1983, 767-770; b) S. V. Myagkota, P. V. Savchin, A. S. Voloshinovskii, T. M. Demkiv, Y. V. Boiko, R. S. Vus, L. S. Demkiv, Phys. Solid State 2008, 50, 1473-1476.

[23] M. Hu, C. Ge, J. Yu, J. Feng, J. Phys. Chem. C 2017, 121, $27053-$ 27058.

[24] K. Thirumal, W. K. Chong, W. Xie, R. Ganguly, S. K. Muduli, M. Sherburne, M. Asta, S. Mhaisalkar, T. C. Sum, H. S. Soo, N. Mathews, Chem. Mater. 2017, 29, 3947-3953.

[25] a) E. R. Dohner, A. Jaffe, L. R. Bradshaw, H. I. Karunadasa, J. Am. Chem. Soc. 2014, 136, 13154-13157; b) Z. Yuan, C. Zhou, Y. Tian, Y. Shu, J. Messier, J. C. Wang, L. J. van de Burgt, K. Kountouriotis, Y. Xin, E. Holt, K. Schanze, R. Clark, T. Siegrist, B. Ma, Nat. Commun. 2017, 8, 1-7; c) M. D. Smith, B. L. Watson, R. H. Dauskardt, H. I. Karunadasa, Chem. Mater. 2017, $29,7083-7087$

[26] a) C. Zhou, H. Lin, H. Shi, Y. Tian, C. Pak, M. Shatruk, Y. Zhou, P. Djurovich, M. H. Du, B. Ma, Angew. Chem. Int. Ed. 2018, 57, 1021-1024; Angew. Chem. 2018, 130,1033-1036; b) B. Kang, K. Biswas, J. Phys. Chem. Lett. 2018, 9, 830-836.

Manuscript received: June 5, 2018

Revised manuscript received: July 6, 2018 Accepted manuscript online: July 12, 2018 Version of record online: July 30, 2018 